\title{
Afscheid van / Farewell to / Adieu à Dirk Beke (1947-2005)
}

Afrika, een droom, een werkelijkheid.

Gedreven verkennen van verre horizonten.

Begrijpen van vreemde mensen, naturen en culturen.

Onderduiken in de avontuurlijke sensatie van de vervreemding.

Een brug willen bouwen van kennis, van inzicht en begrip - tussen generaties - tussen culturen - tussen weten en niet-weten - tussen wetenschappelijke disciplines.

Afrika Brug, een droom over een brug, op peilers van vriendschap, minzame goedheid en een sterk gevoel voor globale rechtvaardigheid naar een beter leven: een recht voor iedereen.

Deze ambitie deelde Dirk, tot aan zijn onverwacht vroege dood ook met ons en wilde hij eveneens in Afrika Focus een blijvende vorm geven, met artisanale gedrevenheid, wetenschappelijke gestrengheid en loyale toewijding, onvermoeibaar de kar trekkend van deze kleine vereniging.

De pijn van het vroege afscheid, ongemeen scherp voor zijn vrouw Katelijne, zijn kinderen Floris, Elise, Jasmine, zijn familie en vrienden blijft.

Zijn droom ook.

Africa, a dream, a reality.

Passionately exploring far away horizons.

Understanding strange peoples, natures and cultures.

Submerging in an adventurous sensation of alienation.

Wanting to build a bridge of knowledge, insight and understanding between generations - between cultures - between the known and the unknown - between scientific disciplines. 
Afrika Brug, a dream about a bridge, on pillars of friendship, amiable goodness and a strong sense of global justice, towards a better life: a right for everyman.

This ambition, Dirk, till his sudden death, shared with us wishing to give it a more stable form in Afrika Focus, with his artisanal enthusiasm, scientific rigour and loyal devotion, carrying with unflagging zeal, the load of this little association.

The pain of this early farewell, sharply felt by his wife Katelijne, his children Floris, Elise and Jasmine, his family and friends, remains.

His dream too.

L'Afrique, un rêve, une réalité.

L'exploration emportée d'horizons lointains.

Comprendre d'autres populations, des natures et des cultures étrangères.

S'immerger dans l'aventure du dépaysement.

Vouloir construire un pont de connaissance, de compréhension et d'intelligence - entre des générations - entre des cultures - entre le connu et l'inconnu - entre les disciplines scientifiques.

Afrika Brug, un rêve fondé sur l'amitié, sur une bonté bienveillante et un sentiment de justice globale pour une vie meilleure: un droit pour chacun.

Dirk, jusqu'à son décès inopiné, partageait cette ambition aussi avec nous en donnant un corps constructif et persistant dans Afrika Focus. Infatigable, il présidait cette petite association avec son enthousiasme, son goût artisanal, sa rigueur scientifique et son dévouement loyal.

$\mathrm{La}$ douleur de son décès, particulièrement intense pour sa femme Katelijne, ses enfants Floris, Elise et Jasmine, sa famille et ses amis, subsiste.

Son rêve aussi.

Morgan De Dapper, Johan De Smedt, Patrick Van Damme, Dominique Godfroid 